\title{
Efficiency of electrical coagulation process using aluminum electrodes for municipal wastewater treatment: a case study at Karaj wastewater treatment plant
}

\author{
Samad Gholami Yengejeh ${ }^{1}$, Hossein Jafari Mansoorian ${ }^{2,3}$, Gharib Majidi ${ }^{1}$, Ahmad Reza Yari ${ }^{*}$, Narges Khanjani ${ }^{5}$ \\ ${ }^{1} \mathrm{MSc}$ of Environmental Health Engineering, Department of Environmental Health Engineering, School of Public Health, Qom \\ University of Medical Sciences, Qom, Iran \\ ${ }^{2}$ Lecturer of Environmental Health Engineering Research Center, Department of Environmental Health, School of Public Health, \\ Kerman University of Medical Science, Kerman, Iran \\ ${ }^{3}$ Young Researchers and Elite Club, Hamedan Branch, Islamic Azad University, Hamedan, Iran \\ ${ }^{4}$ Assistant Professor of Research Center for Environmental Pollutants, Qom University of Medical Sciences, Qom, Iran \\ ${ }^{5}$ Associate Professor of Environmental Health Engineering Research Center, Department of Environmental Health Engineering, School \\ of Public Health, Kerman University of Medical Sciences, Kerman, Iran
}

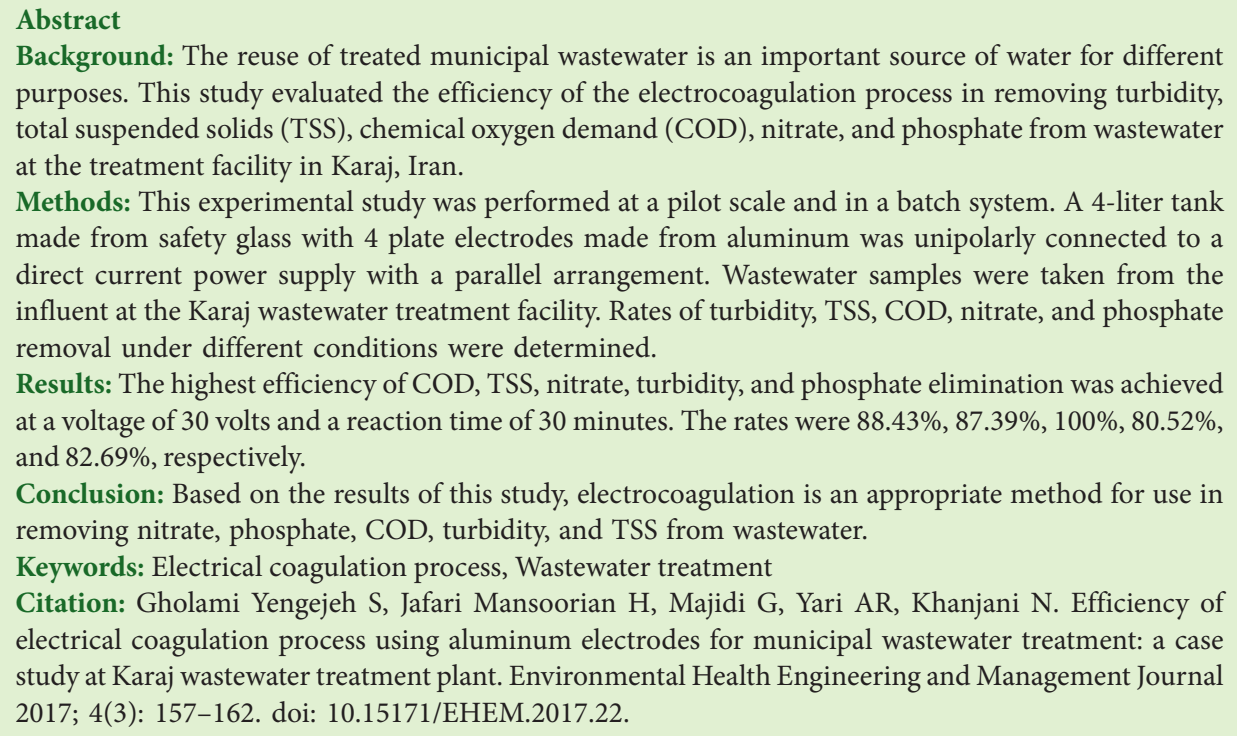

Article History:

Received: 25 December 2016 Accepted: 15 April 2017

ePublished: 10 May 2017

\section{Introduction}

Treated municipal wastewater is a valuable source of water for different purposes such as irrigating agricultural land and green spaces, breeding fish, and artificially recharging underground wastewater (1). Wastewater carries various pollutants that can be classified into the following four groups based on their characteristics: total suspended solids (TSS), non-organic particles, organic particles, and microorganisms (2).

Among the parameters that are important for evaluating the performance of wastewater facilities are the chemical oxygen demand (COD) and nitrogen and phosphorus compounds in the effluent of such treatment units. Or- ganic decomposable materials are always measured according to biological oxygen demand (BOD) and COD. If these materials enter the environment untreated, their biological stability can lead to decreased oxygen resources, anaerobic circumstances, and the dissemination of bad odors as from hydrogen sulfide $(3,4)$.

The phosphate compounds in wastewater become dissolved orthophosphates after hydrolysis and biological degradation which is used in water resources by microorganisms, especially algae. Phosphorus can lead to increased algae growth and eutrophication in bodies of water. Therefore, controlling the growth of algae and preventing eutrophication in water resources by removing 
phosphorus from municipal wastewater can be important factors for saving the quality of limited fresh water resources (5).

Electrocoagulation is the coagulation of material onsite using electrolysis with soluble anode electrodes which are usually made from $\mathrm{Fe}$ or $\mathrm{Al}$ (6). The electrochemical oxidation of $\mathrm{Fe}$ or $\mathrm{Al}$ at the anode makes metal cathodes, but oxidation at the cathode usually makes hydrogen. The electrochemical process includes many chemical and physical phenomena such as electrical discharge, anode oxidation, cathode reduction, coagulation, electrophoresis migration, and surface adsorption. Moreover, in electrocoagulation, the solution does not saturate with anions and its salt content does not increase as with chemical sedimentation (7).

The use of $\mathrm{Al}$ electrodes produced reactions in this study as listed below (6):

$\mathrm{Al}(\mathrm{OH})_{2}^{+}+\mathrm{H}_{2} \mathrm{O} \rightarrow \mathrm{Al}(\mathrm{OH})_{3}+\mathrm{H}^{+}$

$\mathrm{Al}(\mathrm{OH})_{3}+\mathrm{H}_{2} \mathrm{O} \rightarrow \mathrm{Al}(\mathrm{OH})_{4}{ }^{-}+\mathrm{H}^{+}$

$\mathrm{Al}^{3+}+\mathrm{H}_{2} \mathrm{O} \rightarrow \mathrm{Al}(\mathrm{OH})^{2+}+\mathrm{H}^{+}$

$\mathrm{Al}(\mathrm{OH})^{2+}+\mathrm{H}_{2} \mathrm{O} \rightarrow \mathrm{Al}(\mathrm{OH})_{2}^{+}+\mathrm{H}^{+}$

In this process, metal hydroxides are made and combined with pollutants. Bigger clots are formed, and as air bubbles rise to the surface of the reactor, the lighter particles remain floating. Thus, by using the two phenomena of floating and sedimentation, pollutants are removed from the environment (8). Therefore, the mechanism of removal in the electrocoagulation method is the particle instability method which includes electrical double-layer compression, surface adsorption and electrical neutralization, sweeping coagulation, and bridging between particles (9). Meanwhile, the metal hydroxides in the aqua phase remain as a colloid suspension and are able to remove pollutants from wastewater by complexing or electrostatic force (surface adsorption), which leads to coagulation. In the mechanism of forming surface complexes, pollutants as chemicals will make complexes with metal hydrated cations; through sedimentation or floating on the surface of the solution, which leads to the formation of sludge, they will remove pollutants (10). Electrocoagulation has been used successfully to treat the wastewater of industries such as plating, textiles, olive oil production, laundry, tannery, paper and pulp, fermentation, and slaughtering $(6,7)$.

Wang et al evaluated turbidity removal from wastewater at 20 volts and reached a $98 \%$ efficiency (11). Merzouk et al investigated the removal of suspended solids from textile wastewater by using the electrical-coagulation and flotation process and achieved a removal efficiency under optimum conditions $\left(11.55 \mathrm{~mA} / \mathrm{cm}^{2}\right.$ current intensity, 1 $\mathrm{cm}$ space between electrodes, and 10 minutes of contact time) of $86.5 \%$ (12).

Among the advantages of electrical coagulation are the capabilities of adjusting to different situations, selecting, automatic regulation, and compatibility with environmental conditions, simple equipment, high speed, no needing for specific chemicals, small sludge production volumes, short contact time, simple operations, and the capability of treating a wide range of pollutants (7). This study evaluated the efficiency of electrocoagulation using aluminum electrodes for treating municipal wastewater from the Karaj wastewater treatment plant.

\section{Material and Methods}

Sampling and analysis

In this study, combined sampling was performed on the influent of the Karaj wastewater facility. Samples were transferred to the lab in 50-liter polyethylene containers. To prevent any change in quality before analysis, the samples were stirred again. All experiments were done according to the standard methods for the examination of water and wastewater (13). The methods used to analyze each parameter are shown in Table 1.

\section{Electrocoagulation cell}

This study was done experimentally in a plexiglass batch reactor with the dimensions of $16 \times 16 \times 16 \mathrm{~cm}$ and a volume of 4 liters which was resistant to acid. Four unipolar electrodes made from aluminum sheets with the dimensions of $14 \times 14 \mathrm{~cm}$ and a thickness of $0.2 \mathrm{~cm}$ were installed in the reactor and connected to the feeding source unipolarly and parallelly. This pattern consumes less energy in comparison to the series method. In this experiment, the electrical digital converter Matrix Ltd (MPS-30051) which can convert urban electricity to direct electrical current was used. The electricity entering the electrical converter was an alternating current, and the exiting electricity was direct. The Rogale multimeter was used to measure the electrical current. Cell contents were stirred using a Heidolph MR 3001 stirring device at $200 \mathrm{rpm}$. The electrodes were placed $2 \mathrm{~cm}$ away from the base of the reactor so that stirring could be done efficiently.

\section{Electrocoagulation procedure and calculations}

The efficiency of the electrocoagulation process in removing turbidity, TSS, COD, nitrate, and phosphate from wastewater from the Karaj facility was evaluated under the circumstances shown in Table 2.

Table 1. Methods used to analyze each parameter

\begin{tabular}{lllllc}
\hline Pollutant & Unit & Experimental number & Method & Model & Reference \\
\hline Nitrate & $\mathrm{mg} / \mathrm{L}$ & $\mathrm{SM} 4110-\mathrm{B}$ & Spectrophotometer & HACH America & $(13)$ \\
Phosphate & $\mathrm{mg} / \mathrm{L}$ & $\mathrm{SM} 4110-\mathrm{B}$ & Spectrophotometer & HACH America & $(13)$ \\
COD & $\mathrm{mg} / \mathrm{L}$ & $\mathrm{SM} 5220-\mathrm{D}$ & Spectrophotometer & HACH America & $(13)$ \\
TSS & $\mathrm{mg} / \mathrm{L}$ & 2540 & Total solids dried at 103-105 c & - & $(13)$ \\
Turbidity & NTU & SM2130-B & Nephlometry & HACH America & $(13)$ \\
\hline
\end{tabular}


Based on the results of other studies, technical and economic constraints, and the aim of the researcher to deal with a real-time situation, this study evaluated a short contact time with high voltage (contact time: 15 minutes; voltage: $45 \mathrm{~V}$ ), average voltage times with average voltage (contact times: 20 and 30 minutes; voltage: $30 \mathrm{~V}$ ), and a long contact time with low voltage (contact time: 45 minutes; voltage: $15 \mathrm{~V})$.

Samples $(50 \mathrm{~mL})$ were taken from the middle of the reactor. After the end of each experiment, the electrodes were scratched with water, washed with diluted hydrogen chloride, and weighed after washing with distilled water. In Figure 1, the schematic view of the electro-coagulation reactor used in this research is shown.

The electrical energy used is an important economic parameter in the electrocoagulation process; it is calculated using the following formula (14):

$\mathrm{P}=(\mathrm{U} . \mathrm{i} . \mathrm{t}) / \mathrm{V}$

where $P$ is the amount of electricity used (kwh/L), $U$ is the electrical voltage $(\mathrm{V}), I$ is the electrical intensity (A), $t$ is the contact time (h), and $V$ is the volume of wastewater or water (L) for each setting up of the device (14). Also, the number of electrodes used at the end of each experiment was determined by subtracting the initial and final weights.

\section{Results}

The quality indices of the municipal wastewater sampled can be seen in Table 3 .

The present study evaluated the efficiency of the electrocoagulation process using aluminum electrodes in removing COD, TSS, nitrate, turbidity and phosphate from raw municipal wastewater in 3 different situations 1) contact times of 45 and 60 minutes with the potential difference

Table 2. Experimental conditions

\begin{tabular}{ccc}
\hline Contact time (min) & Potential difference (V) & Electrical currency (A) \\
\hline 15 & 45 & 5.3 \\
20 & 30 & 3.4 \\
30 & 30 & 3.4 \\
45 & 15 & 1.5 \\
60 & 15 & 1.5 \\
\hline
\end{tabular}

of $15 \mathrm{~V}$ and electrical currency of $1.5 \mathrm{~A}$; 2) contact times of 20 and 30 minutes with the potential difference of 30 $\mathrm{V}$ and electrical currency of $3.4 \mathrm{~A} ; 3$ ) contact time of 15 minutes with the potential difference of $40 \mathrm{~V}$ and electrical currency of $5.3 \mathrm{~A}$.

The elimination efficiency of nitrate, phosphate, COD, turbidity, and TSS by electrocoagulation is shown in Table 4. As can be seen, with increases in voltage and contact time, the removal rates of nitrate, phosphate, COD, turbidity, and TSSs increased as well. The maximum removal efficiency rates of COD, TSS, nitrate, turbidity, and phosphate were seen under conditions of $30 \mathrm{~V}$ and a reaction time of 30 minutes and were $88.43 \%, 87.39 \%, 100 \%$, $80.52 \%$, and $82.69 \%$, respectively.

Figure 2 presents the number of electrodes used $\left(\mathrm{g} / \mathrm{m}^{3}\right)$ in different voltages. The maximum electrode usage was $2.62 \mathrm{~g} / \mathrm{m}^{3}$ at $45 \mathrm{~V}$ and a contact time of 60 minutes. Figure 3 presents the electrical energy $(\mathrm{kWh} / \mathrm{L})$ consumed in different times and voltages during the electrocoagulation process. The maximum amount of electricity used was $0.095 \mathrm{kWh} / \mathrm{L}$ at 60 minutes and $45 \mathrm{~V}$.

\section{Discussion}

The maximum efficiency for removing turbidity, TSS and COD occurred in 30 minutes of contact time and at $30 \mathrm{~V}$; the minimum efficiency for removing turbidity occurred at $15 \mathrm{~V}$ of potential difference and in a contact time of 45 minutes. As Table 4 shows, at specific reaction times and with increases in electricity voltage, the efficiency of removal increased. Rahmani and Samarghandi studied the efficiency of the electrocoagulation method in removing COD from wastewater; they concluded that by increasing the voltage, the percentage of COD removed increased as well (15). Arbabi et al investigated the electrocoagulation process for treating wastewater from a baker's yeast plant. The COD and turbidity removal efficiency rates turbidity increased with the promotion of current density (16). The results of this study corresponded to those of Rahmani and Samarghandi and those of Arbabi et al. Increasing current density produced larger and heavier flocs. The number of bubbles decreased, but their density increased. As a result, lightweight particles were removed by the bubbles (17). Based on the results of this study, it can be concluded that
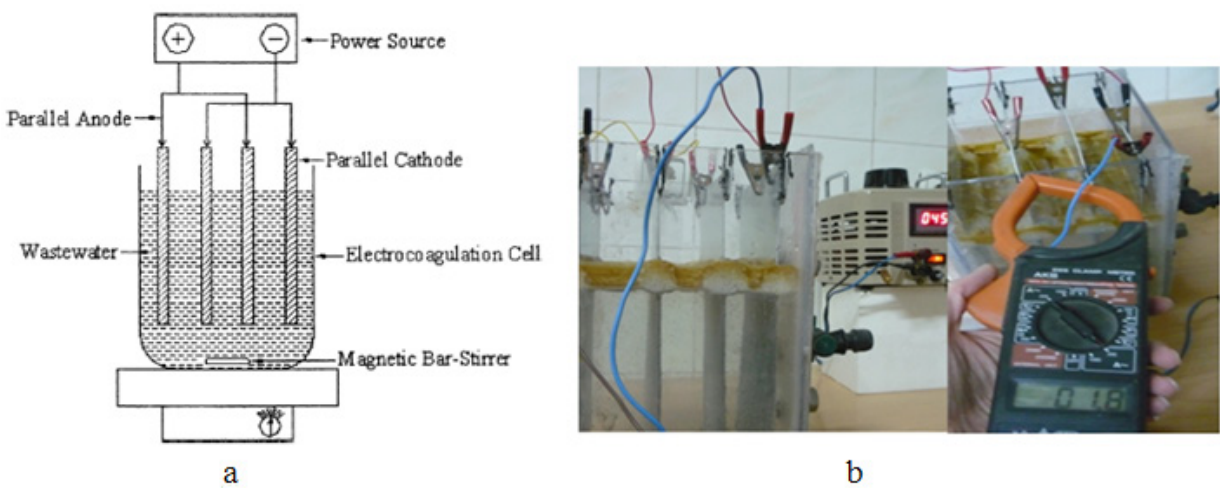

Figure 1. Bench-scale EC reactor with monopolar electrodes in parallel connection (a); image of electrocoagulation (b). 
Table 3. Quality indices of sampled wastewater

\begin{tabular}{lllllll}
\hline Parameter & Unit & Samples number & Minimum & Maximum & Mean \\
\hline Suspended solids & $\mathrm{mgL}^{-1}$ & 9 & 225 & 232 & 165 & 228.3 \\
Turbidity & $\mathrm{NTU}$ & 9 & 152 & 6.52 & 157.5 \\
Phosphate & $\mathrm{mgL}^{-1}$ & 9 & 5.9 & 6.76 & 6.64 \\
Nitrate & $\mathrm{mgL}^{-1}$ & 9 & 415 & 6.5 & \pm 6.57 \\
COD & $\mathrm{mgL}^{-1}$ & 9 & 6.3 & 441 & \pm 0.12 \\
$\mathrm{pH}$ & - & 9 & & 8.1 & \pm 28 \\
\hline
\end{tabular}

Table 4. Effects of potential difference and reaction time on elimination of nitrate, phosphate, COD, turbidity, and suspended solid particles

\begin{tabular}{|c|c|c|c|c|c|c|}
\hline Pollutant & $\begin{array}{l}\text { Reaction time } \\
\text { (min) }\end{array}$ & $\begin{array}{l}\text { Electrical } \\
\text { currency (A) }\end{array}$ & $\begin{array}{l}\text { Potential } \\
\text { difference (V) }\end{array}$ & $\begin{array}{l}\text { Mean concentration of } \\
\text { wastewater entering } \\
\text { electrocoagulation }\end{array}$ & $\begin{array}{l}\text { Mean concentration } \\
\text { of wastewater exiting } \\
\text { electrocoagulation }\end{array}$ & $\begin{array}{l}\text { Mean percent of } \\
\text { elimination }\end{array}$ \\
\hline \multirow{5}{*}{ Nitrate } & 15 & 3.4 & 30 & 6.3 & 1.2 & 80.95 \\
\hline & 20 & 5.3 & 45 & 6.2 & 1.16 & 81.29 \\
\hline & 30 & 3.4 & 30 & 6.5 & 0 & 100 \\
\hline & 45 & 1.5 & 15 & 5.9 & 1.1 & 81.35 \\
\hline & 60 & 1.5 & 15 & 6.1 & 0.5 & 91.80 \\
\hline \multirow{5}{*}{ Phosphate } & 15 & 3.4 & 30 & 6.64 & 1.79 & 73.04 \\
\hline & 20 & 5.3 & 45 & 6.6 & 1.56 & 76.36 \\
\hline & 30 & 3.4 & 30 & 6.76 & 1.17 & 82.69 \\
\hline & 45 & 1.5 & 15 & 6.52 & 1.73 & 73.46 \\
\hline & 60 & 1.5 & 15 & 6.56 & 1.97 & 69.97 \\
\hline \multirow{5}{*}{ COD } & 15 & 3.4 & 30 & 437 & 93 & 78.71 \\
\hline & 20 & 5.3 & 45 & 430 & 76 & 82.32 \\
\hline & 30 & 3.4 & 30 & 441 & 51 & 88.43 \\
\hline & 45 & 1.5 & 15 & 415 & 131 & 68.43 \\
\hline & 60 & 1.5 & 15 & 421 & 121 & 71.25 \\
\hline \multirow{5}{*}{ Turbidity } & 15 & 3.4 & 30 & 159 & 52.96 & 66.69 \\
\hline & 20 & 5.3 & 45 & 158 & 42.83 & 72.89 \\
\hline & 30 & 3.4 & 30 & 163 & 32.56 & 80.52 \\
\hline & 45 & 1.5 & 15 & 152 & 74.5 & 50.99 \\
\hline & 60 & 1.5 & 15 & 155 & 71.73 & 53.72 \\
\hline \multirow{5}{*}{ TSS } & 15 & 3.4 & 30 & 231 & 59.66 & 74.17 \\
\hline & 20 & 5.3 & 45 & 225 & 41 & 81.78 \\
\hline & 30 & 3.4 & 30 & 230 & 29 & 87.39 \\
\hline & 45 & 1.5 & 15 & 229 & 96.33 & 57.93 \\
\hline & 60 & 1.5 & 15 & 226 & 85.66 & 62.1 \\
\hline
\end{tabular}

increasing retention time to 30 minutes increases removal efficiency, but no significant increase in removal efficiency will result when retention time is longer than 30 minutes. Other studies have shown that at a contact time of less than 15 minutes (between $10 \mathrm{~V}$ to $40 \mathrm{~V}$ ), removal efficiency is low, because coagulants do not form; a contact time of more than 60 minutes is not wise because of economic reasons, the formation of many clots, and the possibility of their breakage. Therefore, the appropriate time interval for the electrocoagulation process is between 15 to 60 minutes. Merzouk et al in 2009 (12), Parsa et al in 2011 (18), and El-Ashtoukhy et al in 2010 (19) confirm the above results. In this study, the maximum efficiency for nitrate removal happened at a contact time of 30 minutes and $30 \mathrm{~V}$; the least efficiency occurred at 30 $\mathrm{V}$ and a contact time of 20 minutes. In a study done by Bazrafshan et al, the maximum removal of nitrate from the solution by iron electrodes (96\%) happened at 40 volts, 60 minutes of contact time, and an initial concentration of $5 \mathrm{mg} / \mathrm{L}$ (20). Their study showed that as contact time and potential difference increase, removal rates increase as well, which is similar to the present study. In another study done by Razavi et al on laundry wastewater using electrocoagulation, results showed that using this method with aluminum electrodes can lead to a nitrate removal efficiency of $68 \%$ (21).

In the current study, the maximum efficiency in removing phosphate happened at 30 minutes and $30 \mathrm{~V}$, and the minimum efficiency happened at $15 \mathrm{~V}$ and 60 minutes of contact time. According to these results, increases in voltage have a stronger effect in comparison to reaction time in increasing efficiency. In the study of Takdastan et al about eliminating phosphate, in 90 minutes with $30 \mathrm{~V}$, the efficiency was $99 \%$. They further showed that increases in voltage and reaction time caused increased efficiency (22). Valero and colleagues' study in 2011 (23) confirmed these results.

One of the most important criteria in choosing an appropriate process for removing pollutants is its cost-efficiency; therefore, after each series of experiments with 


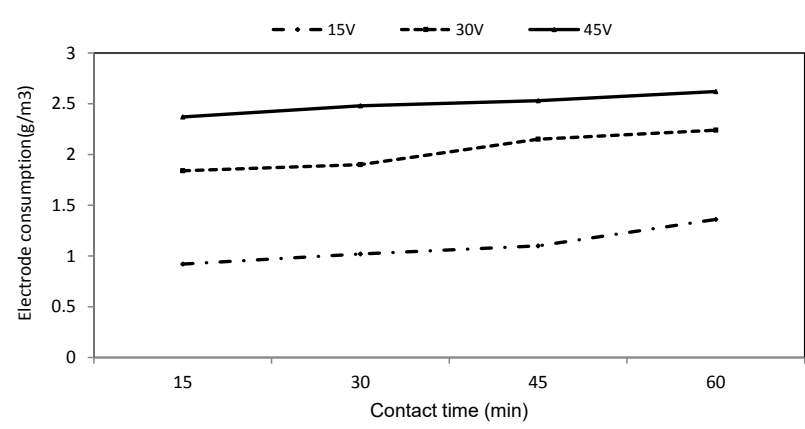

Figure 2. Number of electrodes used at different voltages and contact times.

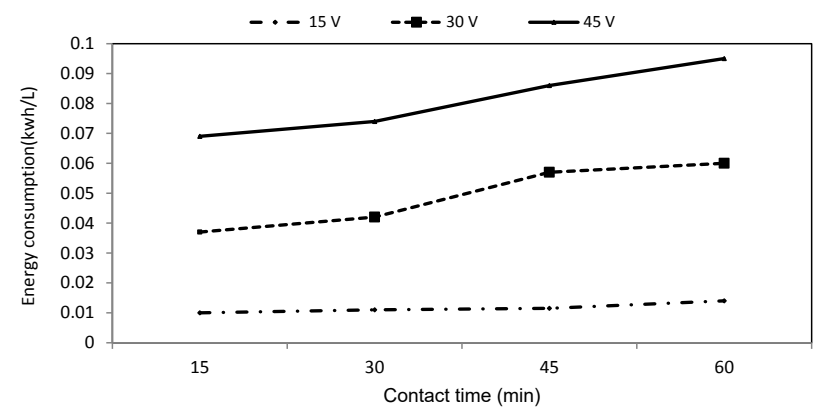

Figure 3. Energy used at different voltages and contact times.

the electrocoagulation process, the aluminum electrodes were weighed and the number of electrodes used under different circumstances was determined. As voltage increased in the process, the number of electrodes used also increased. The maximum amount of decrease in electrode weights happened at $45 \mathrm{~V}$, and the minimum amount happened at $15 \mathrm{~V}$ (Figure 2). The results of Adhoum and Monser on removing phenol compounds using electrocoagulation showed that even though removal efficiency increases with increases in voltage, electrode and energy consumption increases as well (24).

The minimum and maximum amounts of energy consumed were $15 \mathrm{~V}$ and $45 \mathrm{~V}$, respectively. As can be seen in Figure 3, energy consumption is directly correlated with voltage; as voltage increased, electricity consumption increased as well. Increased voltage is related to increased speed of the production of electrolysis products, such as hydrogen in the cathode, and increases in reduction conditions which lead to increased elimination efficiency (25). This finding is in line with those of Pletcher (26) and Malakootian et al (17). Decreases in electrical intensity also occur with increases in electrolysis time; this is related to the surface absorption-reabsorption reaction and blocking currency. This result is in line with those of Walsh (27) and Mahvi et al (28).

\section{Conclusion}

This study evaluated the capabilities of the electrocoagulation method with aluminum electrodes for removing COD, TSS, nitrate, turbidity, and phosphate from municipal wastewater. The results showed that the efficiency of removing pollutants is directly related to increased volt- age and contact time. The efficiency rates of removing COD, TSS, nitrate, turbidity, and phosphate from municipal wastewater using electrocoagulation with aluminum electrodes at $30 \mathrm{~V}$ and 30 minutes of contact time were $88.43 \%, 87.39 \%, 100 \%, 80.52 \%$, and $82.69 \%$, respectively. The results of this research can be used by municipal wastewater facilities.

\section{Authors' contributions}

AY and SGY designed the study. GM and HJM performed the literature search and wrote the manuscript. NK carried out significant improvement in English. All authors participated in data acquisition, analysis, and interpretation. All authors critically reviewed, refined, and approved the manuscript.

\section{Competing interests}

The authors declare that they have no competing interests.

\section{Ethical issues}

The authors certify that all data collected during the study is presented in this manuscript, and no data from the study has been or will be published separately.

\section{Acknowledgments}

The authors wish to thank the Faculty of Health at the Qom University of Medical Sciences for cooperating in this study.

\section{References}

1. Amin MM, Hashemi H, Ebrahimi A, Bina B, Movahhedian Attar H, Jaberi A, et al. Using combined processes of filtration and ultraviolet irradiation for effluent disinfection of Isfahan north wastewater treatment plant in pilot scale. Water and Wastewater 2011; 22(2): 71-7. [In Persian].

2. Nabizadeh R, Nemati R, Aslani H. Effect of potassium permanganate on effectiveness of chitosan in removing of turbidity and fecal coliforms from wastewater. Water and Wastewater 2012; 23(3): 95-102. [In Persian].

3. Tchobanoglous G, Louis F, Burton H, Stensel D. Wastewater Engineering: Treatment and Reuse. 4th ed. NewYork, NY: McGraw-Hill; 2004.

4. Nemerow NL, Agardy FJ, Salvato JA. Environmental Engineering. 5th ed. New Jersey, NJ: John Wiley \& Sons; 2003.

5. Hormozi Nejad M, Takdastan A, Jaafarzadeh Haghighifard N, Ahmadi Mogadam M, Mengelizadeh N. Removal of phosphorus, organic matter and suspended solids by poly aluminum chloride from municipal wastewater (case study: Ahvaz west wastewater treatment plant). Jundishapur J Health Sci 2008; 4(3): 1-13. [In Persian].

6. Jafari Mansoorian H, Mahvi AH, Jonidi Jafari A. Removal of lead and zinc from battery industry wastewater using electrocoagulation process: Influence of direct and alternating current by using iron and stainless steel rod electrodes. Sep Purif Technol 2014; 135: 165-75. doi: 10.1016/j.seppur.2014.08.012.

7. Jafari Mansoorian H, Rajabizadeh A, Bazrafshan E, Mahvi AH. Practical assessment of electrocoagulation process in removing nickel metal from aqueous solutions using iron- 
rod electrodes. Desalination and Water Treatment 2012; 44 (1-3): 29-35. doi: 10.1080/19443994.2012.691708.

8. Emamjomeh MM, Sivakumar M. Review of pollutants removed by electrocoagulation and electrocoagulation/ flotation process. J Environ Manage 2009; 90(5): 1663-79. doi: 10.1016/j.jenvman.2008.12.011.

9. Malakootian M, Jafarzadeh Haghighi Fard N, Ahmadian M, Loloei M. Influence of fenton process on treatability of Kerman city solid waste leachate. Iran J Health Environ 2010; 3(2): 123-34. [In Persian].

10. Kashefialasl M, Khosravi M, Marandi R, Seyyedi K. Treatment of dye solution containing colored index acid yellow 36 by electrocoagulation using iron electrodes. Int J Environ Sci Tech 2006; 2(4): 365-71.

11. Wang CT, Chou WL, Kuo YM. Removal of COD from laundry wastewater by electro coagulation/electro flotation. J Hazard Mater 2009; 164(1): 81-86. doi: 10.1016/j. jhazmat.2008.07.122.

12. Merzouk B, Gourich B, Sekki A, Madani K, Chibane M. Removal turbidity and separation of heavy metals using electrocoagulation-electroflotation technique A case study. J Hazard Mater 2009; 164(1): 215-22. doi: 10.1016/j. jhazmat.2008.07.144.

13. American Water Work Association, APHA. Standard Methods for the Examination of Water and Wastewater. 22th ed. .Washington, DC: APHA; 2012.

14. Martínez SS, Bahenab CL. Chlorbromuron urea herbicide removal by electro-Fenton reaction in aqueous effluents. Water Res 2009; 43(1): 33-40. doi: 10.1016/j. watres.2008.09.036.

15. Rahmani A, Samarghandi MR. Electrochemical removal of COD from effluents. Water and Wastewater 2007; 18(4): 9-15. [In Persian].

16. Arbabi M, Shafiei S, Sedehi M, Mazaheri-Shoorabi E. Investigation electrocoagulation process by using iron and stainless steel electrodes for baker's yeast wastewater treatment. J Shahrekord Univ Med Sci 2014; 16(5): 1-12. [In Persian].

17. Malakootian M, Mansoorian HJ, Moosazadeh M. Performance evaluation of electrocoagulation process using iron-rod electrodes for removing hardness from drinking water. Desalination 2010; 255(1-3): 67-71. doi: 10.1016/j. desal.2010.01.015.

18. Basiri Parsa J, Rezaei Vahidian H. Removal of acid brown 14 in aqueous media by electrocoagulation: optimization parameters and minimizing of energy consumption. Desalination 2011; 278(1-3): 295-302. doi: 10.1016/j. desal.2011.05.040.

19. El-Ashtoukhy ES, Zewail TM, Amin NK. Removal of heavy metal ions from aqueous solution by electrocoagulation using a horizontal expanded $\mathrm{Al}$ anode. Desalination and Water Treatment 2010; 20(1-3): 72-9. doi: 10.5004/ dwt.2010.1127.

20. Bazrafshan E, Soory MM, Mostafapoor F, Mansoorian HJ, Paseban A. Application of aerated electrochemical process to nitrate removal from aqueous. J North Khorasan Univ Med Sci 2011; 3(4): 25-33. [In Persian].

21. Razavi M, Saeedi M, Jabbari E. The effect of operating conditions on simultaneous removal of phosphate, nitrate and COD from laundry wastewater by electrocoagulation using aluminum electrodes. J Environ Stud 2012; 38(3): 75 84. [In Persion].

22. Takdastan A, Azimi A, SalariZ. The use of electrocoagulation process for removal of turbidity, COD, detergent and phosphorus from carwash effluent. Water and Wastewater. 2011; 22(3): 19-25. [In Persian].

23. Valero D, Ortiz M, García V, Expósito E, Montiel V, Aldaz A. Electrocoagulation of wastewater from almond industry. Chemosphere 2011; 84(9): 1290-5. doi: 10.1016/j. chemosphere.2011.05.032.

24. Adhoum N, Monser L. Decolourization and removal of phenolic compounds from olive mill wastewater by electro coagulation. Chem Eng Technol 2004; 43(10): 1281-7. doi: 10.1016/j.cep.2003.12.001.

25. Koparal AS, Ogutveren UB. Removal of nitrate from water by electroreduction and electro coagulation. J Hazard Mater 2002; 89(1): 83-94. doi: 10.1016/S0304-3894(01)00301-6.

26. Pletcher D. Guide to electrochemical technology for synthesis, separation and pollution control. [cited 20 Nov 2016] Available from: https://electrosynthesis.com/ wp-content/uploads/2015/11/guide-to-electrochemicaltechnology.pdf.

27. Walsh FC. Electrochemical technology for environmental treatment and clean energy conversion. Pure Appl Chem 2001; 73(12): 1819-37. doi: 10.1351/pac200173121819.

28. Mahvi AH, Mansoorian HJ, Rajabizadeh A. Performance of electrocoagulation process for removal of sulphate ion from aqueous environments using plate aluminum electrodes. J Qom Univ Med Sci 2009; 4(3): 21-8. [Persian]. 